\title{
Incidence and risk factors of chronic pain following hysterectomy among Southern Jiangsu Chinese Women
}

\author{
Chao $\mathrm{Han}^{\dagger}$, Zhijun $\mathrm{Ge}^{\dagger}$, Wenjie Jiang, Hailong Zhao and Tieliang Ma*
}

\begin{abstract}
Background: Chronic post-surgical pain (CPSP) after hysterectomy has been recognized as a major clinical problem in the Western World. Reports on post-hysterectomy pain are relatively scarce in China. The aim of the current study was to prospectively investigate the incidence and the potential risk factors of CPSP at 3 months following hysterectomy in Chinese population.

Methods: We assessed and collected data on preoperative socio-demographic characteristics, preexisting pain, anxiety and depression, sexual satisfaction, intra-operative variables, and acute postoperative pain intensity in a cohort of 870 women undergoing hysterectomy. The participants were interviewed to determine their suitability to diagnostic criteria of CPSP 3 months later. Logistic regression analyses were subsequently performed to identify predictors for CPSP.

Results: The incidence of CPSP at 3 months after hysterectomy was $27.7 \%$. Most of the women with CPSP suffered from mild pain and had a slight impact on daily life with sleep and emotion functional limitation. Risk factors for CPSP after hysterectomy were preoperative anxiety, depression, pelvic pain, preexisting pain, very-moderate sexual dissatisfaction, and acute postoperative pain at movement. Intra-operative dexmedetomidine infusion with $0.5 \mathrm{\mu g} / \mathrm{kg} / \mathrm{h}$ was associated with a decreased incidence rate of chronic post-hysterectomy pain.

Conclusion: Twenty-eight percent of patients after hysterectomy in southern Jiangsu china had CPSP with 92\% of those women describing it as mild with sleep and emotion functional limitation. Patients with preoperative anxiety and depression, poor sexual satisfaction, preexisting pain, and acute postoperative pain on movement have been identified to be at risk to develop CPSP.
\end{abstract}

Keywords: Chronic post-surgical pain, Hysterectomy, Risk factors

\section{Significance}

Preoperative anxiety and depression, poor sex satisfaction, presence of pre-surgical pain elsewhere, and acute postoperative pain on movement are risk factors for CPSP in a Chinese population.

\section{Background}

Chronic post-surgical pain (CPSP) is a major clinical problem which could lead to impaired physical function and reduced quality of life. Several studies have been published on development of CPSP following hysterectomy in

\footnotetext{
* Correspondence: matieliang@foxmail.com

${ }^{\dagger}$ Equal contributors

The Affiliated Yixing Hospital of Jiangsu University, 75 Tongzhenguan Road, Yixing, Jiangsu 214200, People's Republic of China
}

western population, with the incidence being to be between 5 and $50 \%[1,2]$. The variability in rate of incidence might be due to different study designs and methodologies, selected samples, and CPSP definitions used in individual studies. In China, the annual incidence rate of hysterectomy has been reported to be as high as 80 per 100,000 women, with 250,000 procedures performed each year. This means a high prevalence of chronic posthysterectomy pain in China. However, to date, there have been no reports of prevalence of CPSP following hysterectomy in Chinese population. Moreover, previous studies have demonstrated that differences in the genotype of individuals could influence the development of CPSP [3], indicating that ethnic difference might play an important role in occurrence of CPSP. The published incidence of 
CPSP in western women may therefore not apply to Chinese population. Above all, pertinent knowledge on incidence and risk factors that lead to development of CPSP after hysterectomy among Chinese women is essential for prevention and treatment of chronic posthysterectomy pain in China. The primary aim of this study was to assess chronic pain 3 months after hysterectomy in a cohort of women in China. We also aim to elucidate the relative contribution of clinical and psychological risk factors for the development of CPSP following hysterectomy.

\section{Methods}

\section{Design and study population}

This prospective observational cohort study was approved by the ethics committee of the affiliated Yixing Hospital of Jiangsu University, China. Patients admitted for hysterectomy for benign indications from March 2014 to March 2016 in the affiliated Yixing Hospital of Jiangsu University were invited to participate in this study. Inclusion criteria: (1) age between 18 and 75 years, (2) able to understand consent procedures and questionnaire materials, (3) total or subtotal hysterectomy with or without oophorectomy. Patients who agreed to participate were explained about the procedures, and they signed the consent form. All participants were interviewed in person both preoperatively and $48 \mathrm{~h}$ postoperatively by a trained anesthetist. The follow-up interviews were completed 3 months after surgery. Exclusion criteria were cognitive impairment, a history of cancer, malignant uterine tumors, surgery-related infection.

\section{Preoperative questionnaire}

Study-specific questionnaires were given to the patients for self-administration during the preoperative screening visit before surgery. The questionnaire consisted of questions on patients' age, education, employment, body mass index (BMI), smoking, alcohol abuse, indications for hysterectomy, co-morbidities, and a history of caesarean section, laparotomy or laparoscopy.

Hospital Anxiety and Depression Scale (HADS) in a Chinese version was used for screening anxiety disorders and depression, considering the influence of psychological factors on chronic pain. HADS performed well in assessing symptom severity and in diagnosing anxiety disorders and depression in various populations, with significant internal consistency and concurrent validity [4]. A systematic review and meta-analysis of the association with preoperative anxiety and catastrophizing and Chronic Postsurgical Pain showed that there were no significant difference between HADS and other instruments such as STAI, ICD-9, MSPQ, MMPI [5]. HADS consists of an anxiety subscale (HAD-A) and a depression subscale (HAD-D), each of which contains 7 intermingled items, providing four answer options for each item ranging from 0 to 3 . A cutoff threshold as 8 is identified of possibility of anxiety and depression disorders [6].

The Female Sexual Function Index (FSFI) is the most widely used instrument for female sexual health, comprising six domains: desire, arousal, lubrication, orgasm, satisfaction, and pain [7]. We assessed the degree of sexual satisfaction by means of the 14-16 items of FSFI in a Chinese version [8]. Three questions include how satisfied: (1) with amount of closeness with partner, (2) with sexual relationship, (3) with overall sex life. The score for each item ranges from 1 to 5 . We identified a total score more than 12 as very-moderate satisfied, $8-12$ as about equally satisfied and dissatisfied, and lower than 8 as very-moderate dissatisfied.

\section{Pain questionnaire}

Assessment of pain and its consequences were performed by a trained anesthetist, in face-to-face interviews, before surgery, $48 \mathrm{~h}$ after surgery, and at 3 months after surgery. The Chinese version of brief pain inventory-short form (BPI-SF) was used to estimate the pain severity and the impact on daily life at every interview. The BPI-SF contained 11 items which references pain existed during the past $24 \mathrm{~h}$. It was consisted of 2 subscales: pain severity (NRS: 4 items) and pain interference (7 items). Scores of NRS ranged from 0 to 10 (0 means no pain; 10 means worst pain imaginable).

\section{Surgical variables}

A variety of methods including median lower abdominal approach, Pfannenstiel, vaginal, laparoscopic hysterectomy (LH), or laparoscopic assisted vaginal hysterectomy (LAVH), total or subtotal hysterectomy with or without oophorectomy have been used for removing the uterus and/or ovaries. Anesthetists determined the anesthesia protocol according to the surgery and custom, involving total intravenous anesthesia (TIVA), inhalation anesthesia (IA), epidural anesthesia. Intra-operative sedative and analgesic drugs, duration of operation, blood loss were collected. Postoperative analgesia and complications were also recorded from the hospital database.

\section{Follow-up during $48 \mathrm{~h}$ after surgery}

An experienced anesthetist, who was in charge of pain questionnaire, visited patients within $48 \mathrm{~h}$ after hysterectomy. Pain related data were collected using BPI-SF, including the NRS value at rest and at movement.

\section{Follow-up at $\mathbf{3}$ months after surgery}

BPI-SF was completed, when patients return to hospital at 3 months after hysterectomy. If diagnosed of CPSP, a douleur neuropathic 4-questionnaire (DN-4) was followed to ascertain whether the pain was a neuropathic Pain (NP). 
DN-4 is an instrument evaluating pain characteristics through 10 items, total score being $10[9,10]$. If the patient score is $\geq 4$, neuropathic pain is diagnosed.

\section{Definition of CPSP}

We defined CPSP following hysterectomy based on the diagnosis criteria from the International Association for the Study of Pain (IASP) [11] and proposed by Macrae [12]: (1) pain development after a surgical procedure, (2) pain persisting for more than 3 months, (3) other causes for the pain should be excluded, and d) pain from a pre-existing problem should be explored and exclusion attempted.

\section{Statistical analyses}

SPSS (version 18; Chicago, IL) was used to analyse all data. Categorical data were presented as numbers and percentages. Chi-square tests $\left(\chi^{2}\right)$ were used to analyse socio-demographic, clinical, and psychological measures. Univariate logistic regression analysis was performed to test the influence of possible risk factors on CPSP at 3 months after surgery, and candidate covariates were chosen based on statistical significance or possible clinical importance. Only covariates with $P$-values less than 0.25 in the univariate analysis were entered in the multivariate model. Then, multiple logistic regression analyses were used to determine risk factors for CPSP. Two-sided $P$-values of 0.05 were considered statistically significant.

\section{Results}

From March 2014 to March 2016, 966 patients were recruited in the study. Of the 966 patients, $55(11+5+39)$ were excluded after surgery for the following reasons: (1) surgery cancelled, (2) inability to complete the questionnaire because of postoperative complications or intensive care unit admission, and (3) refusal to continue the whole interview; and another $41(13+8+20)$ were deleted because of: (1) Malignancy outcome, (2) postoperative infection, and (3) follow-up interview 3 months after surgery uncompleted. A total of 870 patients were finally enrolled in the analysis. According to the study definition, of 870 patients, 241 (27.7\%) have been found to have CPSP and the remaining patients $(629 / 870$ $-72.3 \%)$ were free of CPSP 3 months after hysterectomy. Patient inclusion is illustrated in the flow chart in Fig. 1.

Table 1 shows the Characteristics of pain and effect on daily life at 3 months after hysterectomy. 92.1\% (222 of 241) women with CPSP reported mild pain and one tenth of the CPSP patients had a negative impact on

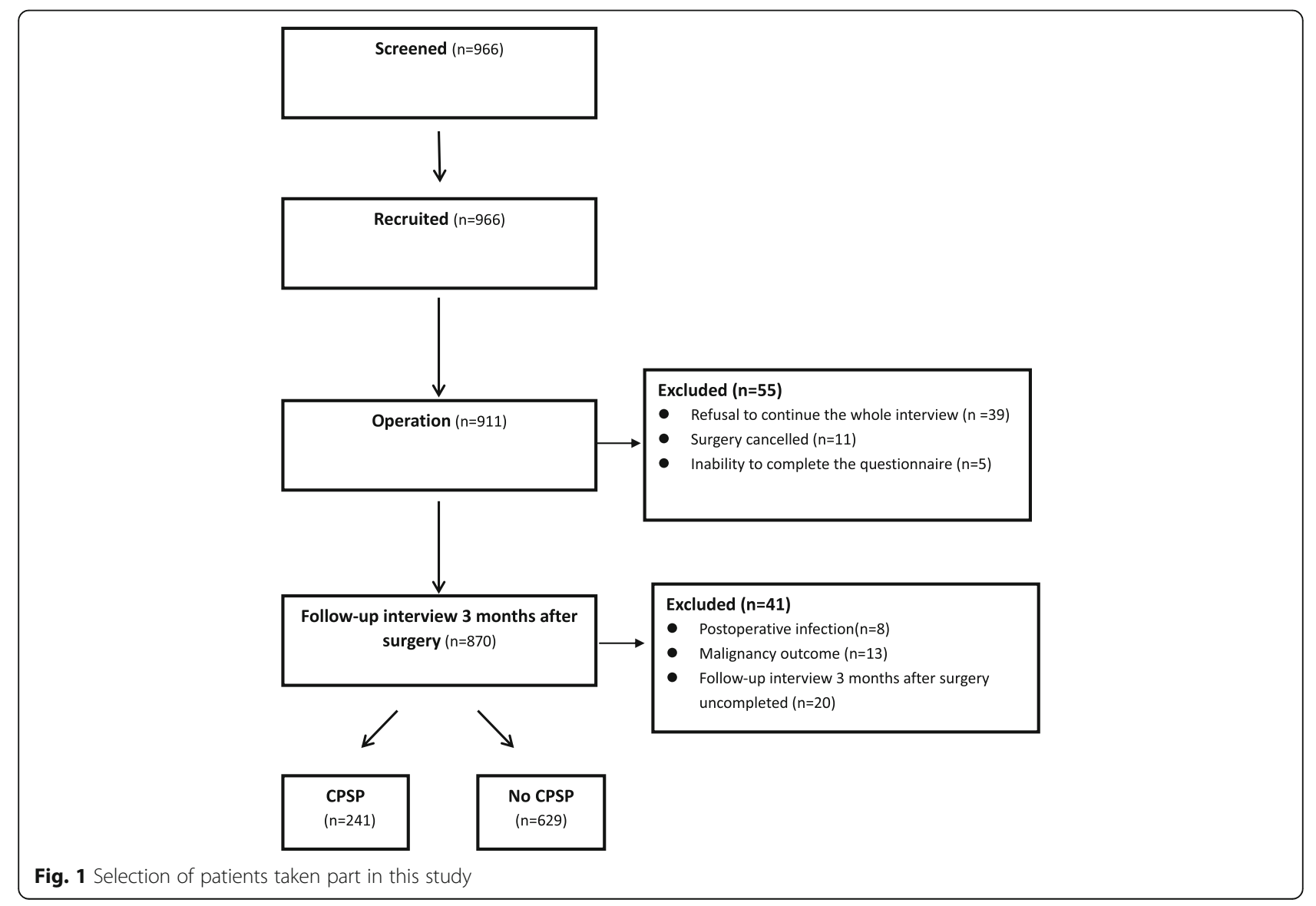


Table 1 Characteristics of pain and impact on daily life at 3 months following hysterectomy

\begin{tabular}{|c|c|}
\hline & $N=241$ \\
\hline \multicolumn{2}{|l|}{ Location } \\
\hline Pelvic region & $113(46.9 \%)$ \\
\hline Area of incision & $86(35.7 \%)$ \\
\hline Vagina & 19 (7.9\%) \\
\hline Lower back & $14(5.8 \%)$ \\
\hline elsewhere & $9(3.7 \%)$ \\
\hline \multicolumn{2}{|l|}{ Frequency } \\
\hline Constantly & $2(0.8 \%)$ \\
\hline Daily & $2(0.8 \%)$ \\
\hline Several times a week & $9(3.7 \%)$ \\
\hline once a week & $22(9.1 \%)$ \\
\hline Less than once a week & $206(85.5 \%)$ \\
\hline \multicolumn{2}{|l|}{ Pain severity (NRS 0-10) } \\
\hline Mild pain (NRS 0-3) & $222(92.1 \%)$ \\
\hline Moderate pain (NRS 4-7) & $17(7.1 \%)$ \\
\hline Severe pain (NRS 7-10) & $2(0.8 \%)$ \\
\hline \multicolumn{2}{|l|}{ DN-4 total score } \\
\hline$<4$ & $127(52.7 \%)$ \\
\hline$\geq 4$ & $114(47.3 \%)$ \\
\hline Analgesic required & $37(15.4 \%)$ \\
\hline Paracetamol & $28(11.6 \%)$ \\
\hline NSAIDs & $9(3.7 \%)$ \\
\hline \multicolumn{2}{|l|}{ Negative impact on daily life } \\
\hline General activity & $16(6.6 \%)$ \\
\hline Mood & $38(15.8 \%$ \\
\hline Walking ability & $15(6.2)$ \\
\hline Normal work & $8(3.3 \%)$ \\
\hline Relations with other people & $22(9.1 \%)$ \\
\hline Sleep & $31(12.9 \%)$ \\
\hline Enjoyment of life & 27 (11.2\%) \\
\hline
\end{tabular}

daily life, mainly on mood and sleep. The most common pain located in pelvic region $(46.9 \%, 113$ of 241$)$ and abdominal scars (35.7\%, 86 of 241). Of 241 patients, 19 $(7.9 \%, \mathrm{NRS} \geq 4)$ were reported moderate to severe pain, $85.5 \%(206 / 241)$ of the patients $(206 / 241)$ reported to be experiencing pain less than once a week. Only 22 of 241 (9.1\%) patients reported analgesic intake. Of 241 patients, $114(47.3 \%)$ presented the characteristics of neuropathic pain with $\mathrm{DN}-4$ score $\geq 4$.

Table 2 presents socio-demographic, clinical, preoperative psychological state, and sexual satisfaction variables for women with and without chronic pain at 3 months after hysterectomy. Factor with a statistically significant association with CPSP included preexisting pain, preoperative anxiety and depression, sexual satisfaction, dexmedetomidine administration, acute pain intensity at movement with $24 \mathrm{~h}$.

As Table 3 shows, 12 variables were included in the subsequent multiple logistic regression models predicting CPSP at 3 months, because $P<0.25$ for the comparisons between patients who did and did not develop chronic persistent pain. The independent predictors for CPSP following hysterectomy were indentified with preoperative pain, anxiety, depression, sexual dissatisfaction, postoperative acute pain intensity NRS $\geq 3$ with $24 \mathrm{~h}$ at movement. Meanwhile, Intra-operative dexmedetomidine infusion with $0.5 \mu \mathrm{g} / \mathrm{kg} / \mathrm{h}$ was associated with a decreased incidence rate of chronic posthysterectomy pain.

\section{Discussion}

In our prospective cohort study conducted on 870 women who underwent hysterectomy, the incidence of CPSP was $27.7 \%$ at 3 months after surgery. Bransborg et al. [13] reported a pain prevalence of $31.9 \% 1$ year after hysterectomy in Denmark in a nationwide questionnaire and database study, and then published a database survey on chronic pain after hysterectomy with a wide range incidence between 4.7 and 31.9\% [1]. However, in another prospective multicenter cohort study in Netherlands, the prevalence of CPSP at 3 months after hysterectomy has been reported to be $10.2 \%$ [14]. The rationale of the lower incidence rate of CPSP was the diagnostic criteria used, and only those patients whose NRS $\geq 4$ at follow-up after 3 months were identified to be experiencing CPSP. In our study, we diagnose CPSP in accordance with the IASP, and the incidence rate of CPSP is close to that in Bransborg report.

The incidence of neuropathic pain ranged widely after various types of surgery. The prevalence of probable or definite neuropathic pain among patients with chronic pain was $52-66 \%$ after thoracic surgery, $68-74 \%$ after breast surgery, $31-45 \%$ after hernia repair, and 6-9\% after total hip and knee arthroplasty [15]. A multicenter cohort study including vaginal and abdominal hysterectomies found that 24 and $44 \%$ of patients with CPSP had neuropathic pain after vaginal and abdominal methods of hysterectomy, respectively [3]. In the current study, nearly half of the patients were assessed to be experiencing neuropathic pain. It has been proposed that different combinations of mechanisms involved in neuropathic and nociceptive pain might cause persistent pain after hysterectomy $[16,17]$, which may probably explain the high pavelance of neuropathic pain in our study.

We found most of patients with CPSP experienced mild pain with a low frequency. A few women reported moderate to severe pain. Pain is localized to the area of surgical incision and pelvis. Our study also found that 
Table 2 Univariate analysis of potential risk factors for CPSP at 3 months after hysterectomy

\begin{tabular}{|c|c|c|c|c|}
\hline & $\begin{array}{l}\text { No-CPSP } \\
629 \\
\end{array}$ & $\begin{array}{l}\text { CPSP } \\
241 \\
\end{array}$ & $x^{2}$ & $P$ \\
\hline \multicolumn{5}{|l|}{ Age } \\
\hline$<45$ & $91(14.5 \%)$ & $44(18.3 \%)$ & 1.924 & 0.382 \\
\hline $45-54$ & $344(54.7 \%)$ & $125(51.9 \%)$ & & \\
\hline$>55$ & $194(30.8 \%)$ & $72(29.9 \%)$ & & \\
\hline \multicolumn{5}{|l|}{ ASA classification } \\
\hline$|-| \mid$ & $606(92.3 \%)$ & 225 (93.4\%) & 3.62 & 0.57 \\
\hline III-IV & $23(3.7 \%)$ & $16(6.6 \%)$ & & \\
\hline \multicolumn{5}{|l|}{ Education } \\
\hline Illiteracy & $63(10.0 \%)$ & $27(11.2 \%)$ & 0.593 & 0.743 \\
\hline Elementary education & $424(67.4 \%)$ & $156(64.7 \%)$ & & \\
\hline High school and above & $142(22.6 \%)$ & $58(24.1 \%)$ & & \\
\hline \multicolumn{5}{|l|}{ Employment } \\
\hline Employed & $272(43.2 \%)$ & $98(40.7 \%)$ & 2.306 & 0.316 \\
\hline Housewife & $103(16.4 \%)$ & $50(20.7 \%)$ & & \\
\hline Retired & $254(40.4 \%)$ & $93(38.6 \%)$ & & \\
\hline \multicolumn{5}{|l|}{ Preoperative pain } \\
\hline Pelvic & $46(7.3 \%)$ & $39(16.2 \%)$ & 74.432 & $<0.001$ \\
\hline Elsewhere & $35(5.65)$ & $53(22.0 \%)$ & & \\
\hline No & $548(87.1 \%)$ & $149(61.8 \%)$ & & \\
\hline \multicolumn{5}{|l|}{ Preoperative analgesic } \\
\hline Paracetamol & $27(4.3 \%)$ & $16(6.6 \%)$ & 6.39 & 0.09 \\
\hline NSAIDs & $21(3.3 \%)$ & $14(5.8 \%)$ & & \\
\hline Opioid & $9(1.4 \%)$ & $6(2.5 \%)$ & & \\
\hline None & $572(90.9 \%)$ & $205(85.1 \%)$ & & \\
\hline \multicolumn{5}{|l|}{ BMI } \\
\hline$<24.44$ & $531(84.45)$ & $197(81.7 \%)$ & 1.052 & 0.591 \\
\hline $24.44-28.08$ & 87 (13.8\%) & $40(16.6 \%)$ & & \\
\hline$>28.08$ & $11(1.7 \%)$ & $4(1.7 \%)$ & & \\
\hline \multicolumn{5}{|l|}{ Smoking } \\
\hline Yes & $24(3.8 \%)$ & $11(4.6 \%)$ & 0.253 & 0.615 \\
\hline No & $605(96.2 \%)$ & $230(95.4 \%)$ & & \\
\hline \multicolumn{5}{|l|}{ Alcohol } \\
\hline Yes & $36(5.7 \%)$ & $9(3.7 \%)$ & 1.405 & 0.236 \\
\hline No & $593(94.3 \%)$ & $232(96.3 \%)$ & & \\
\hline \multicolumn{5}{|l|}{ Indicator for hysterectomy } \\
\hline Myomas & $433(68.8 \%)$ & $150(62.2 \%)$ & 6.073 & 0.415 \\
\hline Menorrhagia & $23(3.7 \%)$ & $11(4.6 \%)$ & & \\
\hline Dysmenorrhoea & $11(1.7 \%)$ & $5(2.1 \%)$ & & \\
\hline Cervical dysplasia & $67(10.7 \%)$ & $39(16.2 \%)$ & & \\
\hline Endometriosis & $25(4.0 \%)$ & $9(3.7 \%)$ & & \\
\hline Uterine prolapsed & $42(6.7 \%)$ & $17(7.1 \%)$ & & \\
\hline Adnexal mass & $28(4.5 \%)$ & $10(4.1 \%)$ & & \\
\hline
\end{tabular}


Table 2 Univariate analysis of potential risk factors for CPSP at 3 months after hysterectomy (Continued)

\begin{tabular}{|c|c|c|c|c|}
\hline \multicolumn{5}{|l|}{ Hypertension } \\
\hline Yes & $69(11.0 \%)$ & $33(13.7 \%)$ & 1.248 & 0.264 \\
\hline No & $560(89.0 \%)$ & $208(86.3 \%)$ & & \\
\hline \multicolumn{5}{|l|}{ Diabetes } \\
\hline Oral medication or diet & $38(6.0 \%)$ & $21(8.7 \%)$ & 2.005 & 0.367 \\
\hline On insulin & $12(2.0 \%)$ & $4(1.7 \%)$ & & \\
\hline No & 579 (92.1\%) & $216(89.6 \%)$ & & \\
\hline \multicolumn{5}{|l|}{ Coronary heart disease } \\
\hline Yes & $7(1.1 \%)$ & $2(0.8 \%)$ & 0.136 & 0.712 \\
\hline No & $622(98.9 \%)$ & $239(99.2 \%)$ & & \\
\hline \multicolumn{5}{|l|}{ Prior caesarean section } \\
\hline Yes & $33(5.2 \%)$ & $21(8.7 \%)$ & 3.598 & 0.058 \\
\hline No & $596(94.8 \%)$ & $220(91.3 \%)$ & & \\
\hline \multicolumn{5}{|l|}{ Prior laparotomy (Not CS) } \\
\hline Yes & $38(6.0 \%)$ & $23(9.5 \%)$ & 3.278 & 0.070 \\
\hline No & $591(94.0 \%)$ & $218(90.5 \%)$ & & \\
\hline \multicolumn{5}{|l|}{ Prior laparoscopy } \\
\hline Yes & $24(3.8 \%)$ & $14(5.8 \%)$ & 1.658 & 0.198 \\
\hline No & $605(96.2 \%)$ & $227(94.2 \%)$ & & \\
\hline \multicolumn{5}{|l|}{ Anxiety (HADS) } \\
\hline Yes & $88(14.0 \%)$ & $55(22.8 \%)$ & 9.893 & 0.002 \\
\hline No & $541(86.0 \%)$ & $186(77.2 \%)$ & & \\
\hline \multicolumn{5}{|l|}{ Depression(HADS) } \\
\hline Yes & $31(4.9 \%)$ & $22(9.1 \%)$ & 5.373 & 0.02 \\
\hline No & $598(95.1 \%)$ & 219 (90.9\%) & & \\
\hline \multicolumn{5}{|l|}{ Sexual satisfaction } \\
\hline Very-moderately satisfied & $337(53.6 \%)$ & 107 (44.4\%) & 16.166 & $<0.001$ \\
\hline Equally satisfied and dissatisfied & $204(32.4 \%)$ & $73(30.3 \%)$ & & \\
\hline Very-moderately dissatisfied & $88(14.0 \%)$ & $61(25.3 \%)$ & & \\
\hline \multicolumn{5}{|l|}{ Type of surgery } \\
\hline lower abdominal & $223(35.5 \%)$ & $86(35.7 \%)$ & 2.479 & 0.648 \\
\hline Pfannenstiel & $158(25.1 \%)$ & $60(24.9 \%)$ & & \\
\hline Vaginal & $76(12.1 \%)$ & $37(15.4 \%)$ & & \\
\hline $\mathrm{LH}$ & $133(21.1 \%)$ & $47(19.5 \%)$ & & \\
\hline LAVH & $39(6.2 \%)$ & $11(4.6 \%)$ & & \\
\hline \multicolumn{5}{|l|}{ Type of anesthesia } \\
\hline TIVA & $168(26.7 \%)$ & $74(30.7 \%)$ & 1.558 & 0.459 \\
\hline IA & $95(15.1 \%)$ & $37(15.4 \%)$ & & \\
\hline Epidural & $366(58.2 \%)$ & $130(53.9 \%)$ & & \\
\hline \multicolumn{5}{|l|}{ Postoperative analgesia } \\
\hline PCEA & $366(58.2 \%)$ & $130(53.9 \%)$ & 1.282 & 0.258 \\
\hline $\mathrm{PCIA}$ & $263(41.8 \%)$ & $111(46.1 \%)$ & & \\
\hline
\end{tabular}


Table 2 Univariate analysis of potential risk factors for CPSP at 3 months after hysterectomy (Continued)

\begin{tabular}{|c|c|c|c|c|}
\hline \multicolumn{5}{|l|}{ Dexmedetomidine } \\
\hline Infusion(0.5 $\mu \mathrm{g} / \mathrm{kg} / \mathrm{h})$ & $109(17.3 \%)$ & $22(9.1 \%)$ & \multirow[t]{3}{*}{10.16} & \multirow[t]{3}{*}{0.006} \\
\hline Bolus $(1 \mu \mathrm{g} / \mathrm{kg})$ & $104(16.5 \%)$ & $37(15.4 \%)$ & & \\
\hline No & $416(66.1 \%)$ & $182(75.5 \%)$ & & \\
\hline \multicolumn{5}{|l|}{ Ketamine } \\
\hline Bolus(1 mg/kg) & $37(5.9 \%)$ & $11(4.6 \%)$ & \multirow[t]{2}{*}{0.581} & \multirow[t]{2}{*}{0.446} \\
\hline No & $592(94.1 \%)$ & $230(95.4 \%)$ & & \\
\hline \multicolumn{5}{|c|}{ Acute pain intensity at rest with $24 \mathrm{~h}$} \\
\hline NRS $<3$ & $511(81.2 \%)$ & $185(76.8 \%)$ & \multirow[t]{2}{*}{2.182} & \multirow[t]{2}{*}{0.14} \\
\hline$N R S \geq 3$ & $118(18.8 \%)$ & $56(23.2 \%)$ & & \\
\hline \multicolumn{5}{|c|}{ Acute pain intensity at movement with $24 \mathrm{~h}$} \\
\hline NRS $<3$ & $464(73.8 \%)$ & $147(61.0 \%)$ & \multirow[t]{2}{*}{13.595} & \multirow[t]{2}{*}{$<0.001$} \\
\hline$N R S \geq 3$ & $165(26.2 \%)$ & $94(39.0 \%)$ & & \\
\hline \multicolumn{5}{|l|}{ Blood loss } \\
\hline$<400 \mathrm{ml}$ & $603(95.8 \%)$ & $228(94.6 \%)$ & \multirow[t]{2}{*}{0.647} & \multirow[t]{2}{*}{0.421} \\
\hline$\geq 400 \mathrm{ml}$ & $26(4.1 \%)$ & $13(5.4 \%)$ & & \\
\hline \multicolumn{5}{|l|}{ Duration of surgery } \\
\hline$<2 \mathrm{~h}$ & $582(92.5 \%)$ & $213(88.4 \%)$ & \multirow[t]{2}{*}{3.802} & \multirow[t]{2}{*}{0.051} \\
\hline$\geq 2 \mathrm{~h}$ & $47(7.5 \%)$ & $28(11.6 \%)$ & & \\
\hline \multicolumn{5}{|l|}{ Blood infusion } \\
\hline Yes & $17(2.7 \%)$ & $9(3.7 \%)$ & \multirow[t]{2}{*}{0.640} & \multirow[t]{2}{*}{0.424} \\
\hline No & $612(95.7 \%)$ & $232(96.3 \%)$ & & \\
\hline
\end{tabular}

CPSP had a slight negative impact on daily life of patients undergoing hysterectomy, particularly in mood and sleep.

Previous research has identified multiple risk factor for CPSP in different surgeries, including age, employment, BMI, education, smoking, preoperative co-morbidities $[2,18-20]$. No significant differences in above mentioned variables were observed between treatments in our study.

Previous surgery has been recognized as a risk factor for development of chronic pain after hysterectomy. In present study, prior surgery including cesarean section, laparoscopy, and laparotomy were associated with chronic pain in univariate but not in multiple logistic regression analyses.

A large body of evidence suggests that the presence of preoperative pain in patients may be related to CPSP [21-24]. Pre-surgical pain predisposes to central sensitization, which has been considered as the underlying mechanism of CPSP. In the current study, we found that the presence of preoperative pain was a risk factor for CPSP after hysterectomy, which supported the findings of Pinto et al. [2].

Psychological factors including anxiety and depression, play a critical role in the development of CPSP [25]. A series of studies published by Brondsborg et al.
[13] showed that preoperative psychological distress was associated with CPSP following hysterectomy [1, 13, 26]. One of the most recent systematic reviews targeting the role of psychosocial predictors of CPSP demonstrates a significant positive association between preoperative anxiety as well as pain catastrophizing and CPSP after hysterectomy [27]. Likewise, pre-surgical depression was considered to relate to an elevated incidence of chronic pain in a prospective cohort study concerning hysterectomy [28]. In the present study, we also found that preoperative anxiety and depression as predisposing factors for the development of chronic pain after hysterectomy.

The effect of hysterectomy on female sexual function has been well studied $[29,30]$. On the contrary, the influence of pre-surgical sexual satisfaction on hysterectomy remains unclear. To our knowledge, we firstly investigated sexual satisfactions of the participants, and found that a very-moderate sexual satisfaction before surgery was an independent predictive factor for CPSP after hysterectomy. Moreover, a preoperative verymoderate sexual dissatisfaction was always associated with pre-surgical pelvic pain, which could explain our findings.

Surgical approach associated with nerve damage has been considered as risk factor for CPSP in many operations. Laparoscopy may minimize the trauma and 
Table 3 Logistic regression model for presence of CPSP at 3 months following hysterectomy

\begin{tabular}{|c|c|c|c|}
\hline & Odds Ratio & 95\% Confidential Interval & $P$ value \\
\hline \multicolumn{4}{|l|}{ Preoperative pain } \\
\hline Pelvic & 3.531 & $2.163-5.763$ & $<0.001$ \\
\hline Elsewhere & 6.227 & $3.814-10.165$ & $<0.001$ \\
\hline None & ref & ref & ref \\
\hline \multicolumn{4}{|l|}{ Alcohol } \\
\hline Yes & 0.709 & $0.317-1.586$ & 0.402 \\
\hline No & ref & ref & ref \\
\hline \multicolumn{4}{|l|}{ Prior caesarean section } \\
\hline Yes & 1.634 & $0.863-3.093$ & 0.132 \\
\hline No & ref & ref & ref \\
\hline \multicolumn{4}{|l|}{ Prior laparotomy (Not CS) } \\
\hline Yes & 1.595 & $0.881-2.887$ & 0.123 \\
\hline No & ref & ref & ref \\
\hline \multicolumn{4}{|l|}{ Prior laparoscopy } \\
\hline Yes & 1.503 & $0.707-3.196$ & 0.290 \\
\hline No & ref & ref & ref \\
\hline \multicolumn{4}{|l|}{ Anxiety (HADS) } \\
\hline Yes & 2.071 & $1.363-3.147$ & 0.001 \\
\hline No & ref & ref & ref \\
\hline \multicolumn{4}{|l|}{ Depression(HADS) } \\
\hline Yes & 2.213 & $1.188-4.123$ & 0.012 \\
\hline No & ref & ref & ref \\
\hline \multicolumn{4}{|l|}{ Sexual satisfaction } \\
\hline Very-moderate satisfied & 0.742 & $0.497-1.107$ & 0.144 \\
\hline Equally satisfied and dissatisfied & ref & ref & ref \\
\hline Very-moderate dissatisfied & 2.366 & $1.476-3.793$ & $<0.001$ \\
\hline \multicolumn{4}{|l|}{ Dexmedetomidine } \\
\hline 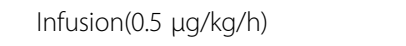 & 0.461 & $0.283-0.753$ & 0.002 \\
\hline Bolus(1 g/kg) & 0.813 & $0.538-1.23$ & 0.327 \\
\hline No & ref & ref & ref \\
\hline \multicolumn{4}{|l|}{ Acute pain intensity at rest with $24 \mathrm{~h}$} \\
\hline NRS $<3$ & ref & ref & ref \\
\hline$N R S \geq 3$ & 0.762 & $0.464-1.251$ & 0.282 \\
\hline \multicolumn{4}{|c|}{ Acute pain intensity at movement with $24 \mathrm{~h}$} \\
\hline NRS $<3$ & ref & ref & ref \\
\hline$N R S \geq 3$ & 2.240 & $1.455-3.446$ & $<0.001$ \\
\hline \multicolumn{4}{|l|}{ Duration of surgery } \\
\hline$<2 \mathrm{~h}$ & ref & ref & ref \\
\hline$\geq 2 \mathrm{~h}$ & 1.458 & $0.786-2.705$ & 0.232 \\
\hline
\end{tabular}

reduce the risk of nerve injury, leading to a decreased incidence of CPSP, which had been verified in laparoscopic hernia repair [31]. Pinto et al. [2] also found vaginal route or laparoscopic approaches of hysterectomy was associated with a lower incidence of CPSP as compared to abdominal hysterectomy, and proposed of the type of hysterectomy as predictive factor of persistent postsurgical pain 4 months following hysterectomy. On the contrary, we did not find contribution of surgical approach to the development of CPSP in our study, 
which was consistent with the findings of Brandsborg [13] and Theunissen [14]. A cross-sectional study to compare CPSP after robot-assisted laparoscopic hysterectomy and abdominal hysterectomy showed that the type of surgical approach did not influence the development of CPSP following hysterectomy [32]. The result supported our opinion from another point of view.

Postoperative epidural analgesia was showed to be related to a reduced incidence of CPSP after abdominal surgery [33]. In our study, we used both epidural analgesia with morphine and intravenous analgesia with sufentanil for treatment of postoperative pain. However, we did not find significant difference in post-hysterectomy analgesia approach between CPSP and No-CPSP, suggesting that the type of postoperative analgesia would not determine the development of CPSP after hysterectomy.

Substantial evidence indicates that intensity of acute postoperative pain was associated with the development of CPSP following hysterectomy [2, 14, 19, 26]. As stated previously, acute postoperative pain NRS $\geq 4$ both at rest and at movement were associated with CPSP in univariate analysis. However, only pain NRS $\geq 4$ at movement was related to CPSP in multiple logistic regression analyses. This result was in agreement with Brandsborg and Theunissen, indicating that postoperative pain management, but not postoperative analgesia approach, plays a critical role in prevention of the development of CPSP.

The effect of anesthetics on development of CPSP is still debatable. Ketamine, an NMDA receptor antagonist, usually used as an adjunct peri-operative analgesic, could reduce the rate of CPSP via a mechanism of preventing peripheral and central sensitizations [34]. Administration ketamine in multi-modal analgesic model did decrease the prevalence of CPSP [35, 36]. However, in a systematic review and meta-analysis of ketamine for the prevention of persistent post-surgical pain, ketamine did not provide a significant reduction of CPSP at 3 and 6 months [5]. In our study, we used ketamine with $1 \mathrm{mg} / \mathrm{kg}$ bolus as an analgesic adjuvant during hysterectomy and did not find the effectiveness of ketamine use on the prevention of CPSP following hysterectomy. Dexmedetomidine, an alpha-2 agonist with analgesic, sedative-hypnotic, and sympatholytic properties, has been investigated to find its effect on acute post hysterectomy pain [37-39]. In a recent randomized clinical trial, pre-emptive dexmedetomidine reduced the incidence of chronic post-thoracotomy pain after coronary artery bypass grafting [40]. In the present study, there were two ways of intra-operative dexmedetomidine administration, infusion with $0.5 \mu \mathrm{g} / \mathrm{kg} / \mathrm{h}$ from anesthesia induction to extubation at the end of surgery and bolus with $1 \mu \mathrm{g} / \mathrm{kg}$ before incision. We also found that intraoperative use of dexmedetomidine infusion with $0.5 \mu \mathrm{g} /$ $\mathrm{kg} / \mathrm{h}$ could decrease the rate of development of CPSP after hysterectomy. It has been reported that dexmedetomidine decrease sympathetic tone and cytokines release to surgical stress [41], which could attenuate peripheral sensitization and central sensitization associated with long-term potentiation and CPSP. Furthermore, in an experimental study, dexmedetomidine modified descending control of nociception by decreasing the threshold for descending inhibition and/or increasing the threshold for descending facilitation [42]. These results may explain that our clinic practice with dexmedetomidine infusion with $0.5 \mu \mathrm{g} / \mathrm{kg} / \mathrm{h}$ decrease the rate of development of CPSP after hysterectomy.

Our study has some limitations that need to be addressed. First of all, the study relied on the subjective self-report, which might be influenced by the psychological and mental status of patients. Second limitation was the data excluded, which could impact the accuracy of the results. Another defect was that most of patients were local residents, therefore, the results of the current study cannot be generalized to women population in China. Lastly, in some cases, economic factors may influence the choice of surgical approach.

Despite these limitations, one advantage of this study was the prospective design. Patients in our study were asked to report pain at interviews, rather than recalling previous pain experiences in retrospective studies. Another merit of this study was the diversity of the treatments, which allows investigating multiple variables.

\section{Conclusion}

In summary, $28 \%$ of patients after hysterectomy in southern Jiangsu china had CPSP with 92\% of those women describing it as mild. Preoperative anxiety and depression, poor sexual satisfaction, presence of pre-surgical pain, and acute postoperative pain on movement are risk factors for development of CPSP in women in China. Intra-operative dexmedetomidine infusion with $0.5 \mu \mathrm{g} / \mathrm{kg} / \mathrm{h}$ is associated with a decreased incidence of chronic post-hysterectomy pain. These results suggest that preventive strategies should be targeted at preoperative psychosocial care and postoperative pain management. A further controlled prospective randomized trial on dexmedetomidine is needed.

\section{Abbreviations}

BMI: Body Mass Index; BPI-SF: Brief Pain Inventory-Short Form; CPSP: Chronic Post-Surgical Pain; DN-4: Douleur Neuropathic 4-Questionnaire; FSFI: Female Sexual Function Index; HAD-A: Hospital Anxiety and Depression Scale- Anxiety subscale; HAD-D: Hospital Anxiety and Depression Scale- Depression subscale; HADS: Hospital Anxiety and Depression Scale; IA: Inhalation Anesthesia; IASP: International Association for the Study of Pain; ICD-9: International Classification Diseases-9; LAVH: Laparoscopic Assisted Vaginal Hysterectomy; LH: Laparoscopic Hysterectomy; MMPI: Minnesota Multiphasic Personality Inventory; MSPQ: Modified Somatic Perception Questionnaire; NMDA: N-methylD-aspartate; NP: Neuropathic Pain; NRS: Numerical Rating Scale; SPSS: Statistical Package for Social Science; STAI: State-Trait Anxiety Inventory; TIVA: Total IntraVenous Anesthesia 


\section{Acknowledgements}

The authors alone are responsible for the content and writing of the paper.

\section{Funding}

This work was supported by Fund of Six Best Talent of Jiangsu, 2016

(WSW-113) and Fund of Science and Technology of Wuxi (CSE31N1522).

\section{Availability of data and materials}

The datasets during and/or analysed during the current study are avaible from the corresponding author on reasonable request.

\section{Authors' contributions}

$\mathrm{CH}$ : study design, conducting experiment, data collection, data analysis, writing the first draft of the paper and giving final approval of the version to be published; ZG: conducting experiment, data collection, assisted with data analysis, manuscript preparation and giving final approval of the version to be published. HZ: did the statistical analysis and manuscript preparation; WJ: collected and formatted the data, assisted with writing the first draft of the paper and giving final approval of the version to be published; TM: Study design, conducting experiment, data collection, data analysis, assisted with writing the first draft of the paper and revising it critically for important intellectual content and giving final approval of the version to be published. All authors read and approved the final manuscript.

\section{Ethics approval and consent to participate}

Institutional Review Board (IRB) of the Affiliated Yixing Hospital of Jiangsu University approved the study (Reference number: 2014-3) and all patients signed informed consent for participation in this study.

\section{Consent for publication}

N/A.

\section{Competing interests}

The authors declare that they have no competing interest.

\section{Publisher's Note}

Springer Nature remains neutral with regard to jurisdictional claims in published maps and institutional affiliations.

\section{Received: 12 April 2017 Accepted: 31 July 2017}

\section{Published online: 11 August 2017}

\section{References}

1. Brandsborg B, Nikolajsen L, Kehlet H, Jensen TS. Chronic pain after hysterectomy. Acta Anaesthesiol Scand. 2008;52(3):327-31.

2. Pinto PR, Mclntyre T, Nogueira-Silva C, Almeida A, Araujo-Soares V. Risk factors for persistent postsurgical pain in women undergoing hysterectomy due to benign causes: a prospective predictive study. J Pain. 2012;13(11):1045-57.

3. Montes A, Roca G, Sabate S, Lao Jl, Navarro A, Cantillo J, Canet J. Genetic and clinical factors associated with chronic postsurgical pain after hernia repair, hysterectomy, and Thoracotomy: a two-year multicenter cohort study. Anesthesiology. 2015;122(5):1123-41.

4. Brennan C, Worrall-Davies A, Mc Millan D, Gilbody S, House A. The hospital anxiety and depression scale: a diagnostic meta-analysis of case-finding ability. J Psychosom Res. 2010;69(4):371-8.

5. Mc Nicol ED, Schumann R, Haroutounian S. A systematic review and metaanalysis of ketamine for the prevention of persistent post-surgical pain. Acta Anaesthesiol Scand. 2014;58(10):1199-213.

6. Yang Y, Ding R, Hu D, Zhang F, Sheng L. Reliability and validity of a Chinese version of the HADS for screening depression and anxiety in psychocardiological outpatients. Compr Psychiatry. 2014;55(1):215-20.

7. Crisp CC, Fellner AN, Pauls RN. Validation of the female sexual function index (FSFI) for web-based administration. Int Urogynecol J. 2015;26(2):219-22.

8. Sun X, Li C, Jin L, Fan Y, Wang D. Development and validation of Chinese version of female sexual function index in a Chinese population-a pilot study. J Sex Med. 2011:8(4):1101-11.

9. Beyaz SG, Özocak H, Ergönenç T, Palabyk O, Tuna AT, Kaya B, Erkorkmaz Ü, Akdemir N. Chronic postsurgical pain and neuropathic symptoms after abdominal hysterectomy. Medicine. 2016;95(33):e4484.
10. Vieira AS, Baptista AF, Mendes L, Silva KS, Gois SC, Lima FM, Souza I, Sa KN Impact of neuropathic pain at the population level. J Clin Med Res. 2014;6(2):111-9.

11. Classification of chronic pain. Descriptions of chronic pain syndromes and definitions of pain terms. Prepared by the International Association for the Study of Pain, subcommittee on taxonomy. Pain Suppl. 1986;3:S1-226.

12. Macrae WA. Chronic pain after surgery. Br J Anaesth. 2001;87(1):88-98.

13. Brandsborg B, Nikolajsen $L$, Hansen $C T$, Kehlet $H$, Jensen TS. Risk factors for chronic pain after hysterectomy: a nationwide questionnaire and database study. Anesthesiology. 2007;106(5):1003-12.

14. Theunissen M, Peters ML, Schepers J, JWM M, Tournois F, van Suijlekom HA, Gramke H-F, MAE M. Recovery 3 and 12 months after hysterectomy. Medicine. 2016;95(26):e3980.

15. Haroutiunian S, Nikolajsen L, Finnerup NB, Jensen TS. The neuropathic component in persistent postsurgical pain: a systematic literature review. Pain. 2013:154(1):95-102.

16. Hagemann $\mathrm{CT}$, Kirste UM. Assessment of persistent pelvic pain after hysterectomy: neuropathic or nociceptive? Scand J Pain. 2016;11:127-9.

17. Pokkinen SM, Nieminen K, Yli-Hankala A, Kalliomäki M-L. Characterization of persistent pain after hysterectomy based on gynaecological and sensory examination. Scand J Pain. 2016;11:42-8.

18. Landau R, Peng Z, Li H, Zhang C, Qian X, Feng Z, Zhu S. A retrospective study of chronic post-surgical pain following thoracic surgery: prevalence, risk factors, incidence of neuropathic component, and impact on qualify of life. PLoS One. 2014;9(2):e90014.

19. Pokkinen SM, Nieminen K, Yli-Hankala A, Kalliomäki M-L. Persistent posthysterectomy pain. Eur J Anaesthesiol. 2015;32(10):718-24.

20. Johannsen M, Christensen S, Zachariae R, Jensen AB. Socio-demographic, treatment-related, and health behavioral predictors of persistent pain 15 months and 7-9 years after surgery: a nationwide prospective study of women treated for primary breast cancer. Breast Cancer Res Treat. 2015;152(3):645-58.

21. Gjeilo KH, Stenseth R, Klepstad P. Risk factors and early pharmacological interventions to prevent chronic postsurgical pain following cardiac surgery. Am J Cardiovasc Drugs. 2014;14(5):335-42.

22. Lewis GN, Rice DA, Mc Nair PJ, Kluger M. Predictors of persistent pain after total knee arthroplasty: a systematic review and meta-analysis. Br J Anaesth. 2015;114(4):551-61.

23. Joris JL, Georges MJ, Medjahed K, Ledoux D, Damilot G, Ramquet CC, Coimbra Cl, Kohnen LP, Brichant JF. Prevalence, characteristics and risk factors of chronic postsurgical pain after laparoscopic colorectal surgery: retrospective analysis. Eur J Anaesthesiol. 2015:32(10):712-7.

24. Fletcher D, Stamer UM, Pogatzki-Zahn E, Zaslansky R, Tanase NV, Perruchoud C, Kranke P, Komann M, Lehman T, Meissner W, et al. Chronic postsurgical pain in Europe: an observational study. Eur J Anaesthesiol. 2015:32(10):725-34.

25. Reddi D, Curran N. Chronic pain after surgery: pathophysiology, risk factors and prevention. Postgrad Med J. 2014:90:222-7.

26. Brandsborg B, Dueholm M, Nikolajsen L, Kehlet H, Jensen TS. A prospective study of risk factors for pain persisting 4 months after hysterectomy. Clin J Pain. 2009;25(4):263-8.

27. Theunissen M, Peters ML, Bruce J, Gramke H-F, Marcus MA. Preoperative anxiety and catastrophizing: a systematic review and meta-analysis of the association with chronic postsurgical pain. Clin J Pain. 2012;28(9):819-41.

28. Vandyk AD, Brenner I, Tranmer J, Van Den Kerkhof E. Depressive symptoms before and after elective hysterectomy. J Obstet Gynecol Neonatal Nurs. 2011;40(5):566-76.

29. Danesh M, Hamzehgardeshi Z, Moosazadeh M, Shabani-Asrami F. The effect of hysterectomy on Women's sexual function: a narrative review. Med Arch. 2015;69(6):387-92

30. Thakar R. Is the uterus a sexual organ? Sexual function following hysterectomy. Sex Med Rev. 2015;3(4):264-78.

31. Jenkins JT, O'Dwyer PJ. Inguinal hernias. BMJ. 2008:336(7638):269-72

32. Sørensen J, Kjeldsen JL, Kugathasan P, Lunde S, Andersen ES, Skov MN, Arendt-Nielsen $\mathrm{L}$. The risk of developing postoperative chronic pain after abdominal and robot-assisted laparoscopic hysterectomy: a cross-sectional study. J Gynecol Surg. 2015;31(4):198-204.

33. Bouman EA, Theunissen M, Bons SA, van Mook WN, Gramke H-F, van Kleef M, Marcus MA. Reduced incidence of chronic postsurgical pain after epidural analgesia for abdominal surgery. Pain Pract. 2014;14(2):E76-84. 
34. Weinbroum AA. Non-opioid IV adjuvants in the perioperative period: pharmacological and clinical aspects of ketamine and gabapentinoids. Pharmacol Res. 2012;65(4):411-29.

35. Akkaya T, Ozkan D. Chronic post surgical pain. OCAK. 2009;2(1):1-9.

36. Lavand'homme P, De Kock M, Waterloos $\mathrm{H}$. Intraoperative epidural analgesia combined with Ketamine provides effective preventive analgesia in patients undergoing major digestive surgery. Anesthesiology. 2005;103:813-20.

37. Ren C, Chi M, Zhang Y, Zhang Z, Qi F, Liu Z. Dexmedetomidine in postoperative analgesia in patients undergoing hysterectomy: a CONSORT-prospective, randomized, controlled trial. Medicine (Baltimore). 2015;94(32):e1348.

38. Cheung CW, Qiu Q, ACL Y, Choi SW, Law WL, Irwin MG. The effects of intraoperative dexmedetomidine on postoperative pain, side-effects and recovery in colorectal surgery. Anaesthesia. 2014;69(11):1214-21.

39. Ge DJ, Qi B, Tang G, Li JY. Intraoperative Dexmedetomidine promotes postoperative analgesia and recovery in patients after abdominal hysterectomy: a double-blind, randomized clinical trial. Sci Rep. 2016;6:21514.

40. Jabbary Moghaddam M, Barkhori A, Mirkheshti A, Hashemian M, Amir Mohajerani S. The effect of pre-emptive Dexmedetomidine on the incidence of post-Thoracotomy pain syndrome in patients undergoing coronary artery bypass grafting. Anesthesiol Pain Med. 2016;6(3):e36344.

41. Mantz J, Josserand J, Hamada S. Dexmedetomidine: new insights. Eur J Anaesthesiol. 2011;28(1):3-6.

42. You HJ, Lei J, Xiao Y, Ye G, Sun ZH, Yang L, Niu N. Pre-emptive analgesia and its supraspinal mechanisms: enhanced descending inhibition and decreased descending facilitation by dexmedetomidine. J Physiol. 2016; 594(7):1875-90.

\section{Submit your next manuscript to BioMed Central and we will help you at every step:}

- We accept pre-submission inquiries

- Our selector tool helps you to find the most relevant journal

- We provide round the clock customer support

- Convenient online submission

- Thorough peer review

- Inclusion in PubMed and all major indexing services

- Maximum visibility for your research

Submit your manuscript at www.biomedcentral.com/submit

) Biomed Central 